\title{
A study of Achievement in English of Tribal students: Comparison of determinants.
}

\author{
Dr. Charlotte Regena John, Prof. B.G. Singh, \\ St. Columba's college Hazaribag, Vinoba Bhave University, Jharkhand, India \\ Pt.Ravishankar Shukla University, Chattisgarh, India.
}

\begin{abstract}
Wide differences exist in the achievement of children from different social backgrounds. Children from more privileged backgrounds tend to achieve better results, make more progress in school than children from deprived background. Tribals take longer time to unfold their abilities as they are deprived of opportunities this may result in intellectual deficiency. In such deprivations, cognitive structure of tribal students might not have developed so they might not feel the need to learn and gain new experiences which resulted in intellectual weakness and this might be the reason that they show low achievement academically. This research explores the effect of personality and emotional intelligence on academic achievement of tribal students. Results imply friendliness, interpersonal management, decisiveness, emotional stability, friendliness, masculinity, heterosexuality, dominance as important predictors in achievement. An understanding of the role of personality and emotional intelligence enables teachers to ensure academic success, motivate students for positive feeling and empathy.
\end{abstract}

Key words: Academic achievement, personality, emotional intelligence.

\section{Introduction}

Tribals in India have to struggle hard for survival and development. They constitute a large number of population so their development is essential for integrated development of the country as a whole. They are deprived of normal opportunities which may result in intellectual weakness. The current number of students who use English as their first language is much less than those who learn English as their second or third language in India the number is seen to recede still lower among tribal students but it is expected to increase in the years to come. A major problem of tribal education is the lack of interest of teachers working in tribal areas. These areas are fairly remote, generally not easily accessible and involve many problems (e.g. poor facilities, living conditions, food, etc.) which discourage even the teachers of tribal and non-tribal origin to work in those regions (Harikrishnan, 1992; Mishra, 1996; Sharma, 2009). Low level of motivation and poor self-concept of children has also been considered as important factors in poor school performance (Annaraja, 1993; Sebastian, 2008). The gap between tribal and non-tribal students in achieving competency is very big and is a major concern which requires strategic intervention. Even today tribals represent the most neglected group of Indian society. During their developmental process, the accumulated assets and liabilities transmitted through generations or acquired through socio-cultural interactions shaped their norms and values of life, and molded their personality dispositions (Baron \& Cohan, 2007; Sebastian, 2008). It has been reported by the center for language of Minority Education and Research 1996 that English learning students find difficulty in language due to a variety of environmental challenges (Jessica R. W, 2006). Thomas and Collier, V.P. (1998) asserted that the average English speaker gains about 10 months of academic growth in one 10-month academic year. Lucy's (2011), work on proficiency and achievement states that personality played a significant role in developing achievement in English language.

\section{Definition of key words}

Academic achievement is the attainment of educational goals by the students and plays a vital role in obtaining ideal harmonious development. The concept of Academic achievement has been studied in the present research considering the marks of $10^{\text {th }}$ board exam in English subject and marks of $1^{\text {st }}$ terminal exam of $11^{\text {th }}$ standard. Personality determines almost all types of behaviour including academic achievement and therefore, in the present research personality has been studied for its influence in academic achievement. Emotional Intelligence improves achievement, productivity and psychological well being in work place of tomorrow by having ability to handle stress. Since few studies on prediction of personality, Emotional intelligence and academic achievement of tribal students has engaged the attention of researches so the present study becomes very significant. Therefore the present study was designed to meet this specific requirement with specific objectives stated as under. 


\section{Statement of the Problem}

"A study of Achievement in English of Tribal students: Comparison of determinants."

\section{Objectives}

The following research objectives guide this study.

1) To study the role of personality, emotional intelligence, gender, locale and culture on Academic achievement in English of adolescent students.

2) To study the comparative role of personality, emotional intelligence gender and locale on Academic achievement in English of Tribal and Non-Tribal adolescent students.

3) To study the comparative role of personality, emotional intelligence, locale and culture on Academic achievement in English of adolescent male and female students.

4) To study the comparative role of personality, emotional intelligence, gender and culture on Academic achievement in English of rural and urban adolescent students.

\section{Hypotheses}

1. There would be no significant role of personality [decisiveness $\left(\mathbf{P}_{\mathbf{1}}\right)$, responsibility $\left(\mathbf{P}_{\mathbf{2}}\right)$, emotional-stability $\left(\mathbf{P}_{3}\right)$, masculinity $\left(\mathbf{P}_{4}\right)$, friendliness $\left(\mathbf{P}_{5}\right)$, hetero-sexuality $\left(\mathbf{P}_{6}\right)$, ego-strength $\left(\mathbf{P}_{7}\right)$, curiosity $\left(\mathbf{P}_{\mathbf{8}}\right)$, dominance $\left(\mathbf{P}_{\mathbf{9}}\right)$ and self-concept $\left(\mathbf{P}_{\mathbf{1 0}}\right)$ ], emotional intelligence [intrapersonal-awareness $\left(\mathbf{E} \mathbf{I}_{\mathbf{1}}\right)$, interpersonal-awareness $\left(\mathbf{E I}_{2}\right)$, intrapersonal-management $\left(\mathbf{E I}_{3}\right)$ and interpersonal-management $\left(\mathbf{E} \mathbf{I}_{4}\right)$ ], gender, locale and culture in determining Academic achievement in English of adolescent students.

2. There would be no significant difference between Tribal and Non-Tribal adolescent students regarding the role of their personality, emotional intelligence, gender and locale in predicting Academic achievement in English.

3. There would be no significant difference between Male and Female adolescent students regarding the role of their personality, emotional intelligence, locale and culture in predicting Academic achievement in English.

4. There would be no significant difference between Urban and Rural adolescent students regarding the role of their personality, emotional intelligence, gender and culture in predicting Academic achievement in English.

\section{Methodology}

Research Design - This is a co-relational research including dependent variable Academic achievement in English. Independent variables in the study were culture (Tribal and Non-tribal), gender (Male and female), locale (Urban and Rural), personality (ten-dimensions) and emotional intelligence (four-dimensions).

Sample - Participants included randomly drawn 604 students, studying in class XI from forty government higher secondary schools situated in Jharkhand. They were from rural $(\mathrm{N}=301)$ and urban $(\mathrm{N}=303)$ schools. Among them 304 were male and 300 were females; 303 were tribals and 301 were non-tribals, age ranging from 15.5 to 17.5 .

\section{Tools -}

1. To assess the Emotional Intelligence "Mangal Emotional Intelligence Inventory" by Mangal (2004) was used. It measured Emotional Intelligence through 100 items, of 25 items for each of the four areas as :

(i) Intrapersonal awareness $\left(\mathrm{EI}_{1}\right)$ is the ability to recognize one's own emotions.

(ii) Interpersonal awareness $\left(\mathrm{EI}_{2}\right)$ is to establish and maintain positive, mutual relationships like intimacy and giving and receiving affection.

(iii) Intrapersonal management $\left(\mathrm{EI}_{3}\right)$ is the ability to realize over own capacities and strive to achieve personal goals.

(iv) Interpersonal management $\left(\mathrm{EI}_{4}\right)$ is the ability to manage and regulate self and others in stressful adverse situation without falling apart, to cooperate and help others in the group.

2. Personality of the subjects was measured by "Singh's Differential Personality Inventory" by Singh (2002). This inventory assesses personality in ten dimensions, namely-

(i) Decisiveness is the ability to take quick decision. (ii) Responsibility is the number of behavioral syndromes like finishing a task in time. (iii) Emotional-Stability is the control over emotions. (iv) Masculinity is the ability to handle challenges. (v) Friendliness refers to the level of empathy. (vi) Hetero sexuality is the extent to which a person can actively work with members of opposite sex. (vii) Ego-strength is the ability to coordinate high behaviour thoughts and actions. (viii) Curiosity is found in those who explore details of objects. (ix) Dominance 
is a trait in which a person tends to be a leader. (x) Self concept is what we thing we are, what we think others think of us and what we would like to be.

3. Academic achievement Measure- The marks of $10^{\text {th }}$ board exam were taken as a measure for Academic Achievement in English subject ad also marks obtained in the $11^{\text {th }}$ terminal exams.

All the hypotheses formulated were examined with the help of Multiple Regression Analysis Report of this analysis is depicted in Tables 1, 2, 3, 4 and figures 1 to 4 simultaneously.

\section{Determinants Of Academic Achievement In English}

Regression results for achievement in English have been depicted in table 1.

Table 1. Multiple Regression Analysis with English Achievement and Independent Variables

\begin{tabular}{|c|c|c|c|c|c|c|}
\hline Variables & b coefficient & $\beta$ & $\mathbf{r}$ & Explained variance \% & $t$ & sig. \\
\hline Constant & 50.631 & - & - & - & 10.218 & s \\
\hline Gender & .403 & .018 & .117 & 0.210 & .473 & ns \\
\hline Locale & 6.253 & .273 & .332 & 9.063 & 6.889 & s \\
\hline Culture & 9.975 & -.435 &. .654 & 28.445 & 6.729 & s \\
\hline$P_{1}$ (Decisiveness) & .166 & .040 & .592 & 2.368 & .871 & ns \\
\hline $\mathbf{P}_{2}($ Responsibility $)$ & -.850 & -.192 & .452 & 8.678 & 4.678 & s \\
\hline $\mathbf{P}_{3}$ (Emotional Stability) & .445 & .098 & .543 & 5.321 & 2.556 & $\mathrm{~s}$ \\
\hline $\mathbf{P}_{4}$ (Masculinity) & -.334 & -.087 & -.136 & 1.183 & 2.491 & s \\
\hline $\mathbf{P}_{5}($ Friendliness $)$ & .168 & -.033 & .232 & 0.765 & 1.107 & ns \\
\hline $\mathbf{P}_{6}($ Hetero sexuality $)$ & -.212 & .063 & . .243 & 1.530 & 2.132 & s \\
\hline $\mathbf{P}_{7}($ Ego strength $)$ & .107 & .024 & .424 & 1.017 & .727 & ns \\
\hline $\mathbf{P}_{8}($ Curiosity $)$ & .056 & 0.012 & .335 & 0.402 & .361 & ns \\
\hline $\mathbf{P}_{9}($ Dominance $)$ & -.004 & .001 & .421 & 0.042 & .030 & ns \\
\hline$P_{10}($ Self concept $)$ & .103 & .029 & .548 & 1.589 & .756 & ns \\
\hline EI $_{1}$ (Intrapersonal Awareness) & .130 & .044 & .525 & 2.31 & 1.011 & ns \\
\hline EI $_{2}$ (Interpersonal Awareness) & .311 & .105 & .599 & 6.289 & 2.450 & s \\
\hline $\mathbf{E I}_{3}$ (Intrapersonal management) & .040 & .020 & .391 & 0.782 & .624 & ns \\
\hline $\mathbf{E I}_{4}($ Interpersonal management) & .343 & .116 & .583 & 6.762 & 3.018 & $\mathrm{~s}$ \\
\hline
\end{tabular}

$$
\mathrm{ns}=\text { not significant }, \quad \mathrm{s}=\text { significant }, \mathrm{p}<.05
$$

Table (1) revealed the value of ' $\mathrm{R}$ ' as .770 , ' $\mathrm{F}$ ' as $50.260(\mathrm{p}<.0001)$, ' $\mathrm{R}$ ', as .593 , explaining $59.3 \%$ variance in achievement in English. Significant variables were locale $[b=6.25, \beta=.27, p<.0001]$, culture $[b=$ 9.97, $\beta=-.43, p<.0001]$, Responsibility $\left(\mathrm{P}_{2}\right)[\mathrm{b}=-.85, \beta=-.19, \mathrm{p}<.0001]$, Emotional stability $\left(\mathrm{P}_{3}\right)[\mathrm{b}=.44, \beta=$ $.09, \mathrm{p}<.01]$, Masculinity $\left(\mathrm{P}_{4}\right)[\mathrm{b}=-.33, \beta=-.08, \mathrm{p}<.01]$, Heterosexuality $\left(\mathrm{P}_{6}\right)[\mathrm{b}=-.21, \beta=.06, \mathrm{p}<.05]$, Interpersonal awareness $\left(\mathrm{EI}_{2}\right)[\mathrm{b}=.31, \beta=.10, \mathrm{p}<.01]$ and Interpersonal management $\left(\mathrm{EI}_{4}\right)[\mathrm{b}=.34, \beta=.11, \mathrm{p}$ $<.01]$. Significant negative $\mathrm{b}$ coefficient for Responsibility, Masculinity and Heterosexuality indicated that higher these factors lower would be the achievement in English. Positive significant b coefficient indicated that an increase in these factors increased the achievement in English. This result is highlighted in graphical form in Fig.1. Locale and culture explained $9.06 \%$ and $24.44 \%$ variance in achievement in English respectively, whereas Responsibility, Emotional stability, Masculinity, Heterosexuality, Interpersonal awareness and Interpersonal management explained $8.67 \%, 5.32 \%, 1.18 \%, 1.53 \%, 6.28 \%, 6.76 \%$ variance in English achievement respectively.

Fig. 1: Role of Independent Variables on English achievement of students

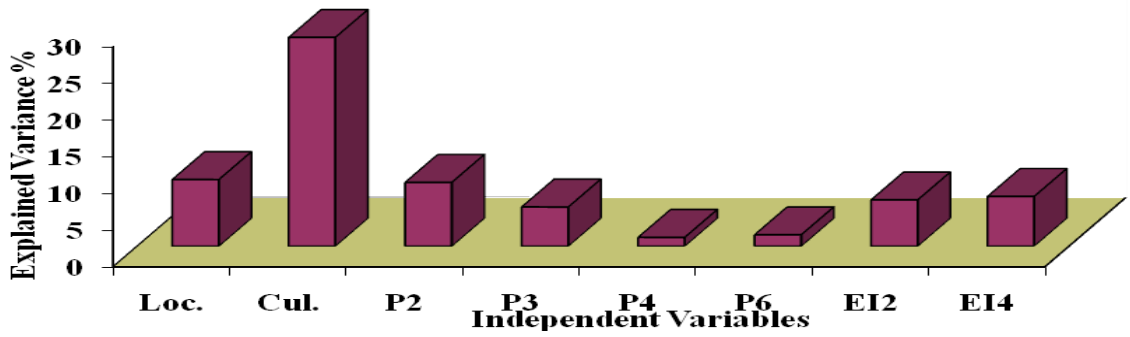

Discussion (a)

Results clearly show that locale had a positive role and culture had significant negative role in determining English achievement. Emotional stability, Interpersonal awareness and Interpersonal management 
showed positive significance in determining English achievement. Responsibility, Masculinity and Heterosexuality had significant negative role in English achievement. On the other hand personality factors like Ego strength, Curiosity and Self concept had insignificant role in all cases and therefore null hypotheses regarding these factors has been accepted by the findings of the present research. But results regarding other personality factors have been found to support the null hypotheses partially.

\section{Comparison of Determinants of English Achievement of Tribal and Non-Tribal Students}

Results of Multiple Regression Analysis conducted separately for tribal and non-tribal students are presented side by side for comparison in Table 2.

Table 2: Comparison of Regression coefficient of Achievement in English for Tribal and Non-Tribal Students

\begin{tabular}{|c|c|c|c|c|c|c|}
\hline \multirow[b]{2}{*}{ Variables } & \multicolumn{3}{|c|}{ Tribal } & \multicolumn{3}{|c|}{ Non-tribal } \\
\hline & $\begin{array}{c}\text { b } \\
\text { coefficient }\end{array}$ & $\boldsymbol{\beta}$ & EV\% & $\begin{array}{c}\text { b } \\
\text { coefficient }\end{array}$ & $\beta$ & EV\% \\
\hline Gender & $-.518 \mathrm{~ns}$ & -.038 & .387 & $2.600 \mathrm{~ns}$ & .128 & 2.329 \\
\hline Locale & $2.003 \mathrm{~ns}$ & .146 & 2.934 & $9.000 \mathrm{~s}$ & .442 & 27.094 \\
\hline$P_{1}$ & $.503 \mathrm{~s}$ & .150 & 3.180 & $.309 \mathrm{~ns}$ & .058 & 1.653 \\
\hline $\mathbf{P}_{2}$ & $-.474 \mathrm{~ns}$ & .166 & 1.909 & $-.204 \mathrm{~ns}$ & -.033 & .297 \\
\hline $\mathbf{P}_{3}$ & $.446 \mathrm{~ns}$ & .116 & 1.833 & $.045 \mathrm{~ns}$ & .010 & .316 \\
\hline $\mathbf{P}_{4}$ & $.075 \mathrm{~ns}$ & .019 & .057 & $-.130 \mathrm{~ns}$ & -.049 & .955 \\
\hline $\mathbf{P}_{5}$ & $.474 \mathrm{~s}$ & .147 & 2.675 & $.146 \mathrm{~ns}$ & .030 & .429 \\
\hline $\mathbf{P}_{6}$ & $.193 \mathrm{~ns}$ & .097 & .116 & $-.599 \mathrm{~s}$ & -.196 & 7.761 \\
\hline $\mathbf{P}_{7}$ & $-.272 \mathrm{~ns}$ & -.088 & .255 & $.248 \mathrm{~ns}$ & .054 & 1.139 \\
\hline $\mathbf{P}_{8}$ & $.040 \mathrm{~ns}$ & .017 & .074 & .006 ns & .001 & .013 \\
\hline $\mathbf{P}_{9}$ & $-.097 \mathrm{~ns}$ & -.040 & .088 & $-.136 \mathrm{~ns}$ & -.028 & .571 \\
\hline $\mathbf{P}_{10}$ & $.216 \mathrm{~ns}$ & .080 & 1.576 & $-.022 \mathrm{~ns}$ & -.005 & .118 \\
\hline $\mathbf{E I}_{1}$ & $.115 \mathrm{~ns}$ & .046 & .602 & $.239 \mathrm{~ns}$ & .065 & .884 \\
\hline $\mathbf{E I}_{2}$ & $.181 \mathrm{~ns}$ & .069 & 1.104 & $.313 \mathrm{~ns}$ & .081 & 2.324 \\
\hline $\mathbf{E I}_{3}$ & $.032 \mathrm{~ns}$ & .032 & .412 & $.030 \mathrm{~ns}$ & .008 & .211 \\
\hline $\mathbf{E I}_{4}$ & $.384 \mathrm{~s}$ & .189 & 4.781 & $.311 \mathrm{~ns}$ & .078 & 2.683 \\
\hline $\begin{array}{l}R=.408 \\
R^{2}=.167\end{array}$ & $\begin{array}{l}F=(16,286) \\
=3.577\end{array}$ & $\mathrm{p}<.0001$ & & $\begin{array}{l}R=.678 \\
R^{2}=.459\end{array}$ & $\begin{array}{l}F= \\
(16,284) \\
=15.08\end{array}$ & $\mathrm{p}<.0001$ \\
\hline
\end{tabular}

ns = not significant,$\quad \mathrm{s}=$ significant, at $\mathrm{p}<.05$

Multiple correlation coefficient (R) for tribals was found to be .408 which was significant [F $(16,286)$ $=3.577, \mathrm{p}<.0001]$ (Table 2$)$. Its square $\left(\mathrm{R}^{2}\right)$ was .167 which indicated that all the significant variables included in the present analysis contributed to $16.7 \%$ variance in English achievement of tribal students. R for nontribals was found to be .678 which was significant $[\mathrm{F}(16,284)=15.081, \mathrm{p}<.0001]$. Its square $\left(\mathrm{R}^{2}\right)$ was .459 which indicated that all the significant variables included in the present analysis contributed to $45.9 \%$ variance in English achievement in non-tribal students. Beta weight of significant variables of Tribals revealed that Interpersonal management (.189) emerged as the most important determinant of English achievement which was followed by Decisiveness (.150) and finally by Friendliness (.147). Whereas 'Beta weight' of the significant 'b coefficient' in Non-Tribals showed that locale (.442) emerged as the most important determinant of English achievement which was followed by Hetero sexuality (-.196). A graph was drawn as shown below in Fig. 2 on the basis of significant variables and their explained variance. On the $\mathrm{X}$-axis, the significant independent variables namely, locale, decisiveness $\left(\mathrm{P}_{1}\right)$, friendliness $\left(\mathrm{P}_{5}\right)$, heterosexuality $\left(\mathrm{P}_{6}\right)$ and interpersonal management $\left(\mathrm{EI}_{4}\right)$ and on $\mathrm{Y}$-axis, the explained variances were taken. 
Fig.2: Comparison of Explained Variance in English Achievement by different significant Variables in Tribal and Non-Tribal students

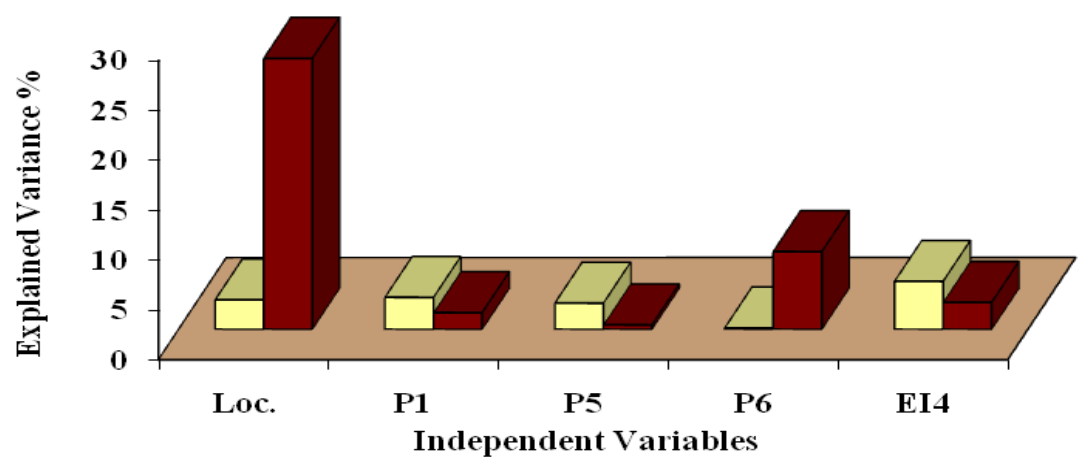

Discussion (b): Results reveal that 'Locale' positively affected non-tribal students' achievement in English but did not affect tribal achievement as tribals in urban and rural areas behaved in the same manner they follow and keep their traditions intact and being in urban or rural areas does not seem to be a hindrance in their way of living same attitude is seen in their academic front. Decisiveness, Friendliness and Interpersonal management had a positive significant role in determining achievement in English in tribal students. Heterosexuality showed negative role in determining Non-tribal student's achievement whereas it was found to be insignificant factor in tribals since in tribal society intermixing among opposite sex was a common factor which is promoted in the society

\section{Comparison of Determinants of English Achievement in Male and Female Students}

Regression Analysis results regarding English achievement of Male and Female students' are presented in Table 3 and Fig. 3.

Table 3: Comparison of Regression Coefficient of English achievement in Male and Female students

\begin{tabular}{|c|c|c|c|c|c|c|}
\hline \multirow[b]{2}{*}{ Variables } & \multicolumn{3}{|c|}{ Male } & \multicolumn{3}{|c|}{ Female } \\
\hline & $\begin{array}{c}\text { b } \\
\text { coefficient }\end{array}$ & $\beta$ & $\begin{array}{c}\text { Explained } \\
\text { Variance\% } \\
\end{array}$ & $\begin{array}{c}\text { b } \\
\text { coefficient }\end{array}$ & $\beta$ & $\begin{array}{c}\text { Explained } \\
\text { Variance\% } \\
\end{array}$ \\
\hline Locale & $9.346 \mathrm{~s}$ & .400 & 14.24 & $4.705 \mathrm{~s}$ & .213 & 6.66 \\
\hline Culture & $-8.051 \mathrm{~S}$ & -.344 & 20.296 & $-11.638 \mathrm{~s}$ & -.527 & 38.41 \\
\hline $\mathbf{P}_{1}$ & $.114 \mathrm{~ns}$ & .028 & 1.685 & $.246 \mathrm{~ns}$ & .057 & 3.41 \\
\hline $\mathbf{P}_{2}$ & $-1.398 \mathrm{~s}$ & -.326 & 11.833 & $-.266 \mathrm{~ns}$ & -.059 & 3.43 \\
\hline $\mathbf{P}_{3}$ & $1.009 \mathrm{~s}$ & .225 & 13.005 & $-.036 \mathrm{~ns}$ & -.007 & 0.34 \\
\hline $\mathbf{P}_{4}$ & $-.280 \mathrm{~ns}$ & -.055 & 1.974 & $.001 n s$ & .001 & .052 \\
\hline $\mathbf{P}_{5}$ & $.530 \mathrm{~s}$ & .098 & 1.127 & $.255 \mathrm{~ns}$ & .054 & 1.74 \\
\hline $\mathbf{P}_{6}$ & $-.123 \mathrm{~ns}$ & -.038 & .809 & $-.020 \mathrm{~ns}$ & -.006 & .153 \\
\hline $\mathbf{P}_{7}$ & $-.009 \mathrm{~ns}$ & -.023 & .828 & $.265 \mathrm{~ns}$ & .057 & 2.88 \\
\hline $\mathbf{P}_{8}$ & $.163 \mathrm{~ns}$ & .039 & 1.368 & $.023 \mathrm{~ns}$ & .005 & 0.137 \\
\hline$P_{9}$ & $.203 \mathrm{~ns}$ & .055 & 2.794 & $-.108 \mathrm{~ns}$ & -.026 & 0.762 \\
\hline $\mathbf{P}_{10}$ & $.129 \mathrm{~ns}$ & .039 & 2.113 & $-.103 \mathrm{~ns}$ & -.025 & 1.36 \\
\hline $\mathrm{EI}_{1}$ & $.066 \mathrm{~ns}$ & .024 & 1.322 & $.185 \mathrm{~ns}$ & .054 & 3.08 \\
\hline $\mathbf{E I}_{2}$ & $.437 \mathrm{~s}$ & .153 & 8.965 & $.254 \mathrm{~ns}$ & .084 & 5.19 \\
\hline $\mathrm{EI}_{3}$ & $-.113 \mathrm{~ns}$ & -.041 & 2.095 & $.063 \mathrm{~ns}$ & .039 & 1.38 \\
\hline $\mathbf{E I}_{4}$ & $.344 \mathrm{~s}$ & .124 & 6.795 & $.403 \mathrm{~s}$ & .127 & 7.91 \\
\hline $\begin{array}{l}R=.760 \\
R^{2}=.578\end{array}$ & $\begin{aligned} F & =(16,284) \\
& =24.571\end{aligned}$ & $\mathrm{p}<.0001$ & & $\begin{array}{l}R=.806 \\
R^{2}=.650\end{array}$ & $\begin{array}{l}F=(16, \\
283) \\
=32.888\end{array}$ & $\mathrm{p}<.0001$ \\
\hline
\end{tabular}

$\mathrm{ns}=$ not significant,$\quad \mathrm{s}=$ significant,$\quad$ at $\mathrm{p}<.05$ 
To examine the significant difference between both the $\mathrm{R}_{\mathrm{s}}$ i.e. Multiple correlation coefficient for male and female students, F test was used with Ferguson's formula and the obtained value was 59.016 [p $<.0001$ ], which indicated that variables in study had differential role for male and female students. In Table (3) it was clear that the male students explained $57.8 \%$ variance which was less important than female students with an explained variance of $65.0 \%$ thus the explained variance was found to be less capable in explaining male student's English achievement (see Fig.3). Value of Beta weight showed that locale (.400) was the most important determinant of English achievement in male students, which was followed by 'culture' (-.344), then Responsibility (-.326), Emotional stability (.225), Interpersonal awareness (.153), Interpersonal management (.124) and finally Friendliness (.098). Beta weight of significant variables showed that 'culture' (-.527) was found to be the most important determinant of English achievement of female students, followed by locale (.213) and finally by Interpersonal management (.127). On comparing the value of ' $b$ coefficient' for significant variables it was found that role of 'locale' exhibited positive significant relationship with both male and female students' English achievement which indicated that urban male and female students' English achievement was more importantly determined than their rural male and female counterparts. 'Culture' exhibited a significant negative relationship with both male and female students, i.e. non-tribal male and female participants English achievement was more importantly determined than tribal male and female participants. Friendliness and Interpersonal awareness and Interpersonal management revealed a positive significance in English achievement in male students but an insignificant relationship in female students was seen. A graph was drawn as shown below in Fig. 3 on the basis of significant variables and their explained variance. On the X-axis, the significant independent variables namely, locale, culture, responsibility $\left(\mathrm{P}_{2}\right)$, emotional stability $\left(\mathrm{P}_{3}\right)$, friendliness $\left(\mathrm{P}_{5}\right)$, interpersonal awareness $\left(\mathrm{EI}_{2}\right)$ and interpersonal management $\left(\mathrm{EI}_{4}\right)$ and on $\mathrm{Y}$-axis, their respective explained variances were taken. In Table 3 decisiveness, responsibility emotional stability, masculinity, heterosexuality, ego strength, curiosity, dominance, self concept, Intrapersonal awareness, Interpersonal awareness and Intrapersonal management were found to be insignificant in explaining variances in English achievement of female students so null hypothesis $\mathrm{H}_{3}$ is being accepted in these cases.

Fig. 3: Comparison of Explained Variance in English Achievement by different significant variables in Male and Female Students

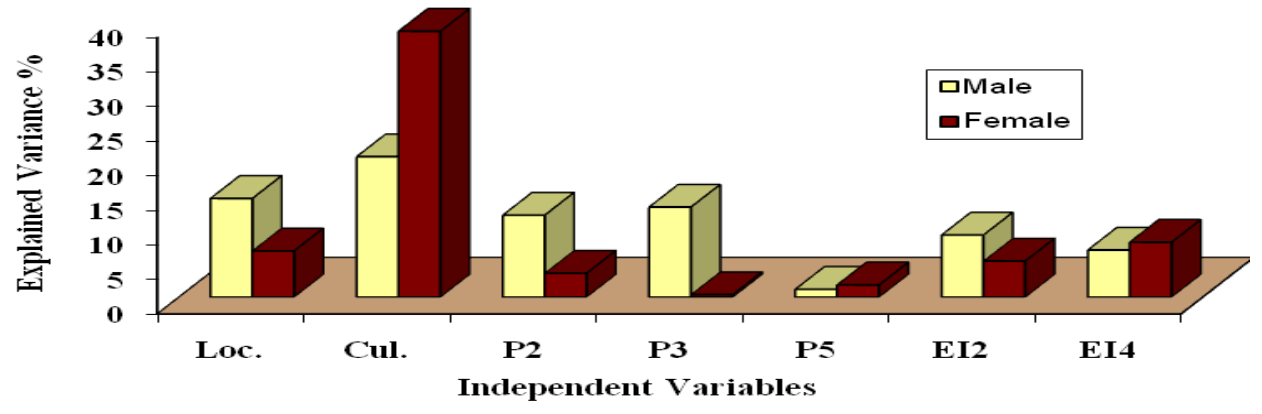

DISCUSSION (c): Above results shows that the hypothesis regarding demographic and physiological variables supported partially the findings of the present study. Significant role of locale in male and female achievement found in the present research expressed that achievement of urban male and female students was more specifically defined as the facilities were better in the urban scenario than in the rural areas. Role of culture was found to be negative in female and male showing that non- tribal male and female achievement was more highly determined than the tribal male and females. Negative role of Responsibility related with male achievement indicated that as the responsibility increased the male student got involved with many other factors which kept him behind academically but responsibility was found to be insignificant in female indicating that achievement of female sex was not affected by high responsibility i.e. females are capable of taking stress strain and tensions and still are able to maintain a stable life and improve academically. Friendliness, Interpersonal awareness and Interpersonal management was found to be related to male achievement indicating male students more capable in maintaining friendly relationships and thus attaining more opportunities in developing emotional traits needed for enhancing their achievement, whereas female are not able to be socially active due to the society norms and thus they lag behind in many fields of attaining achievement but were better in interpersonal management. 


\section{Comparison of Determinants of English Achievement in Urban and Rural Students}

Regression analysis of achievement of students from Urban and Rural selected for the present study was conducted to examine Objective 4. Results obtained are depicted simultaneously for the purpose of comparison, in Table 4 and Figure 4.

Table 4: Comparison of Regression Coefficient of English achievement of Urban and Rural students

\begin{tabular}{|c|c|c|c|c|c|c|c|}
\hline \multirow{2}{*}{ Variable } & \multicolumn{4}{|c|}{ URBAN } & \multicolumn{3}{|c|}{ RURAL } \\
\hline & $\begin{array}{c}\mathrm{b} \\
\text { coefficient }\end{array}$ & & $\beta$ & $\mathrm{EV} \%$ & $\begin{array}{c}\mathrm{b} \\
\text { coefficient }\end{array}$ & $\beta$ & $\mathrm{EV} \%$ \\
\hline Gender & $.154 \mathrm{n}$ & ns & .061 & .5002 & $1.797 \mathrm{~ns}$ & .105 & 2.131 \\
\hline Culture & $-12.45 \mathrm{~s}$ & $\mathrm{~s}$ & -.492 & 38.523 & $-8.764 \mathrm{~s}$ & -.513 & 30.267 \\
\hline $\mathrm{P}_{1}$ & $.431 \mathrm{n}$ & ns & .084 & 5.04 & $.222 \mathrm{~ns}$ & .069 & 3.291 \\
\hline $\mathrm{P}_{2}$ & $-.073 \mathrm{n}$ & ns & -.010 & 0.406 & $-.411 \mathrm{~ns}$ & -.141 & 5.950 \\
\hline $\mathrm{P}_{3}$ & $-.206 \mathrm{n}$ & ns & -.037 & 1.864 & $.330 \mathrm{~ns}$ & .094 & 3.534 \\
\hline $\mathrm{P}_{4}$ & $.073 \mathrm{n}$ & ns & .017 & 0.139 & $-.378 \mathrm{~s}$ & -.132 & 3.141 \\
\hline $\mathrm{P}_{5}$ & $.726 \mathrm{~s}$ & $\mathrm{~s}$ & .125 & 4.137 & $.109 \mathrm{~ns}$ & .029 & .806 \\
\hline $\mathrm{P}_{6}$ & $-.160 \mathrm{n}$ & ns & -.039 & 0.218 & $-.226 \mathrm{~ns}$ & -.087 & 2.244 \\
\hline $\mathrm{P}_{7}$ & $-.280 \mathrm{n}$ & ns & -.052 & 2.657 & $.170 \mathrm{~ns}$ & .055 & 1.749 \\
\hline $\mathrm{P}_{8}$ & $-.191 \mathrm{n}$ & ns & -.045 & 1.894 & $-.020 \mathrm{~ns}$ & -.006 & .154 \\
\hline $\mathrm{P}_{9}$ & $.332 \mathrm{n}$ & ns & .080 & 4.568 & $-.448 \mathrm{~s}$ & -.146 & 2.306 \\
\hline $\mathrm{P}_{10}$ & $.100 \mathrm{n}$ & ns & .025 & 1.455 & $.005 \mathrm{~ns}$ & -.002 & .080 \\
\hline $\mathrm{EI}_{1}$ & $.426 \mathrm{~s}$ & $\mathrm{~s}$ & .124 & 7.762 & $-.108 \mathrm{~ns}$ & -.049 & 1.607 \\
\hline $\mathrm{EI}_{2}$ & $.217 \mathrm{n}$ & ns & .072 & 4.874 & $.129 \mathrm{~ns}$ & .052 & 2.251 \\
\hline $\mathrm{EI}_{3}$ & $.043 \mathrm{n}$ & ns & .023 & 0.692 & $.018 \mathrm{~ns}$ & -.008 & .347 \\
\hline $\mathrm{EI}_{4}$ & $.294 \mathrm{n}$ & ns & .089 & 5.402 & $.367 \mathrm{~s}$ & .158 & 7.473 \\
\hline $\begin{array}{l}R=.811 \\
R^{2}=.629\end{array}$ & $\begin{array}{c}F=(16,286 \\
=34.469\end{array}$ & & $p<.0001$ & & $\begin{array}{l}R=.681 \\
R^{2}=.464\end{array}$ & $\begin{array}{r}F= \\
28 \\
=\end{array}$ & \begin{tabular}{l|l} 
& $p<$ \\
& .0001 \\
55 &
\end{tabular} \\
\hline
\end{tabular}

$$
\mathrm{ns}=\text { not significant, } \quad \mathrm{s}=\text { significant at } \mathrm{p}<.05
$$

To examine the significant difference between both the $\mathrm{R}_{\mathrm{s}}$ i.e. Multiple correlation coefficient for urban and rural students, F test was used with Ferguson's formula and the obtained value was 163.865 , [p $<.0001]$ which indicated that variables in study had differential role for urban and rural students. Multiple correlation coefficient $(R)$ for urban students was .811 which was significant $[F(16,286)=34.469, p<.0001]$. Its square $\left(\mathrm{R}^{2}\right)$ was .659 which indicated that all the significant variables included in the present analysis contributed to $65.9 \%$ variance in English achievement of urban students, $(\mathrm{R})$ for rural students was .681 which was significant $[\mathrm{F}(16,284)=16.385, \mathrm{p}<.0001]$. Its square $\left(\mathrm{R}^{2}\right)$ was .464 which indicated that all the significant variables included in the present analysis contributed to $46.4 \%$ variance in English achievement of rural students. Beta weight of significant variables showed that the most important determinant of English achievement in urban students was Culture (-.492) which was then followed by Intrapersonal awareness (.124) and Friendliness (.125). Beta weight of significant variables indicated that most important determinant of English achievement in rural students was, 'Culture' (-.513), followed by Interpersonal management (.158), then Dominance (-.146) and finally Masculinity (-.132). Explained variance percentage was $65.9 \%$ in urban and $46.4 \%$ in rural students indicating that the variables in the study were more important in determining English achievement in urban students. Significant variables that explained English achievement in urban students were culture, friendliness and Intrapersonal awareness where as significant variables that explained English achievement in rural students were masculinity, dominance and Intrapersonal management. A graph was drawn as shown below in Fig. 21 on the basis of significant variables and their explained variance. On the $\mathrm{X}$-axis, the significant independent variables namely, culture, masculinity $\left(\mathrm{P}_{4}\right)$, friendliness $\left(\mathrm{P}_{5}\right)$, Dominance $\left(\mathrm{P}_{9}\right)$, Intrapersonal awareness $\left(\mathrm{EI}_{1}\right)$ and Interpersonal management $\left(\mathrm{EI}_{4}\right)$ and on $\mathrm{Y}$-axis, their respective explained variances were taken. 
Fig. 4: Comparison of Explained Variance in English Achievement by different significant variables in Urban and Rural Students

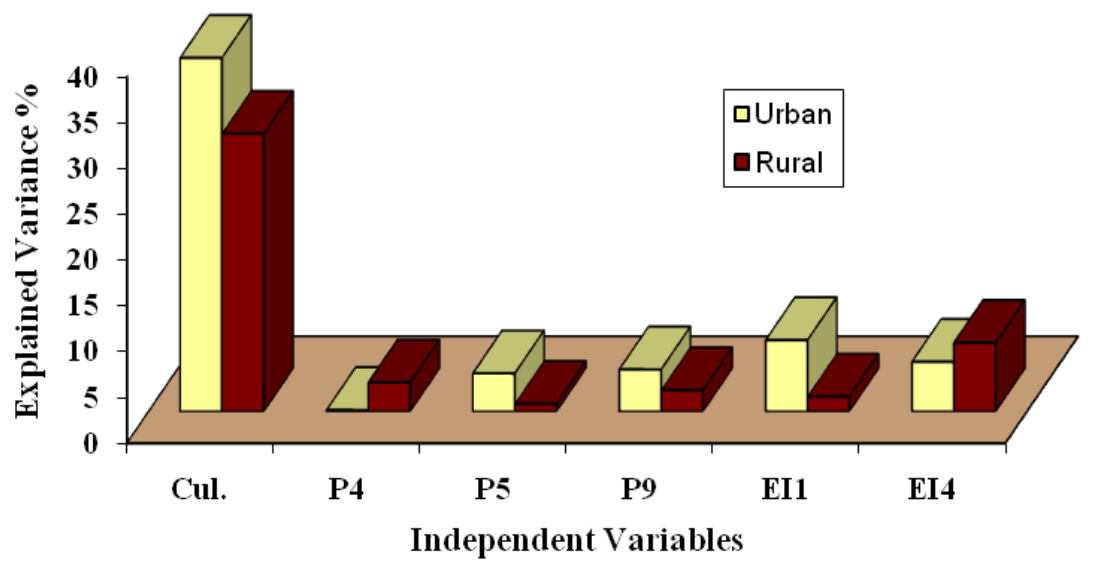

DISCUSSION (d): Comparison of the significant variables of urban and rural students in Table 4 revealed that Culture was negatively significant in urban and rural students indicating that the English achievement in tribal students was more importantly determined by culture. Role of Friendliness and Intrapersonal awareness was significant for urban students but not for rural. Masculinity and Dominance was negatively significant and Intrapersonal management was positively significant in determining English achievement in rural students only. An insignificant role of Responsibility, Emotional stability, Heterosexuality, Ego strength, Curiosity, and Self concept was observed in both urban and rural students' academic achievement and therefore null hypotheses regarding these factors has been accepted by the findings of the present research. But results regarding other personality factors have been found to support the null hypotheses partially. The role of Intrapersonal awareness in urban students it was found to have a significant positive effect but in rural students its insignificant role was seen. Intrapersonal management had an insignificant role in urban students but positive significant effect was seen in rural student achievement in English.

Insignificance of gender in determining urban students achievement indicated that gender difference has diminished in the urban scenario but in the rural front it is still has a major role to play where still the male child is given all the special care and attention of parents thinking that the son will take care of them in their old age and the daughter was to be prepared to take care of the family and also due to dowry system prevalent in Jharkhand rural parents are less interested in investing money in the female Childs education. Culture was found to be negatively related to both urban and rural student's achievement as till now the tribals are found to be socially and morally subdued due to the suppression they faced for centuries which has disturbed their natural and healthy growth.

The gap between tribal and non-tribal students in achieving competency is wide and is a major concern which requires strategic intervention. By developing Emotional intelligence from childhood, one can make a happier and more successful adult so with an understanding of Emotional intelligence and acceptable personality traits we can shape the educational process to benefit all students and teachers for immediate and long term achievement. The cross-cultural differences in achievement in different dimensions of educational performance should draw the attention of educators, especially teachers who teach in a multicultural (non-tribal - tribal) context. These teachers should be aware of cultural group differences in addition to individual difference. To increase the performance of tribal students, efforts should be made at local level to train them in self-awareness that would facilitate them to realize their own potential capacities leading to better performance in all the subjects. The present study suggests training students to strive to achieve personal goals and actualize ones potential can be made possible.

It would also be beneficial if teachers are educated upon the importance of empathy so they can teach students to understand, appreciate and be aware of others feelings especially towards their differently abele counterparts. This can be achieved by telling real life instances, giving students tasks that require them to utilize particular emotions that one wants to develop for example, priority setting tasks (for decisiveness), group exercises (for friendliness), making plans (for responsibility), community work (for inter and intrapersonal 
awareness and management), project work (for curiosity), organizing activities (for dominance and selfconcept), etc. Students can also directly learn when they realize the importance of empathy, moreover that just because someone appearance, thoughts, activities and culture is different from the way they think, it does not mean that the person thinks more poorly or better. Students gain a sense of self-efficacy when they learn about cultural differences, because they realize that there is nothing wrong with the way they are or think, what is more important is to make the most of it in whatever state he/she is in. Teachers can also promote student learning through modeling effective behaviour as they have the most influence on children so can help them in gaining higher scores in different subjects which may result in the betterment of their performance.

This study may also influence educational programmers to emphasize the importance of enhancing academic achievement by the development of required personality traits and emotional intelligence in the student's life directly. It would be of great help for teachers, educational administrator's educational planners and policy-makers, guidance workers and counselors. The level of motivation for academic achievement would provide them an insight to launch academic competitive programs from which their potentialities could be adjudged and necessary remedial teaching including enrichment programmes could be imparted. The nature and kind of motivations could provide an insight to the guidance workers and counselors, and to enhance their motivational levels by implying various techniques and would also help them to design their vocational placement and problems of adjustment in life. Since many of the students may play the role of student leaders, and thereby derive their need satisfaction, it is equally useful to all professional personnel who are in some way or other responsible for maintaining law and order and assigning suitable reinforcement system.

\section{Research Implications Of The Findings}

The sample chosen was restricted to students of Jharkhand board affiliated schools in Jharkhand State India. Other samples should be used in future attempts to replicate and extend the results of this study; for example, students from other States, educational systems and also from college students. Since socio-economic status was not taken into consideration, its effect on academic achievement could not be controlled. Also, nothing was known about the socio-economic status of the families constituting the students in the sample. The results of this study also point to the direction for future researches. For example, researchers should investigate such questions as -

- Exactly how do students from tribal and non-tribal cultures formulate their achievement?

- What and how do cultural factors contribute to the development of personality?

- Comparison of personality profiles of students from different tribal groups?

- Cross cultural comparative study of Personality traits and EI of Higher Secondary students of other states.

- A Study of Non-enrolment, Wastage and Stagnation during the First Two Years of Primary Education of tribal Boys and Girls in Chhattisgarh State.

- Cross cultural study of Intellectual / Non-Intellectual Factors in Academic achievement of the Advantaged / Disadvantaged students of Professional College.

- A Psychological Basis Study of Educational and Vocational Development of Tribals.

- A Study of Family Structure, Parental Behaviour and Conservatism in Tribal and Non-Tribal College Students of Santal Parganas.

- These questions merit further qualitative and quantitative investigation. Answers to these questions can contribute to the research field of Emotional intelligence and personality and enable educators to use their knowledge to facilitate more effective teaching and learning.

\section{References}

[1]. Bar-On, R., Cote. Minears. (2007). Effect of Emotional Stability on Emotional intelligence. On Multy Health System Inc.

[2]. Bharsakle, S. (1995). Need achievement motivation in tribal and non-tribal high school students. Indian Journal of Psychology, 70(3 $\& 4), 97-103$.

[3]. Borbora, R. D. (2001). Influence of parental literacy on the academic achievements of children belonging to the backward classes. Journal of Indian Education, XXVII(1), 59-65.

[4]. Chakravarthi, S. Chatterjee, R. G. (2008). A cross cultural study on Tribals. Journal of social work .50,143-153.

[5]. Coley, R. (2001). Differences in the gender gap: Comparisons across racial/ethnic groups in education and work. Princeton: Educational Testing Service, Policy Information Center.

[6]. Collier, V.P.(1995). Acquiring second language for school. Directions in language and education, 1,4

[7]. Devanesan, P. (1990). Socio-economic status, achievement motivation and scholastic achievement of higher secondary students in Pasumpon Thevar Thirumagan district. In NCERT (1997), Fifth survey of educational research. New Delhi: NCERT, 1869.

[8]. Education Commission. (1964-1966). Education and National development. New Delhi: NCERT.

[9]. Ford, D. Y. (1996). Reversing under-achievement among gifted Black students. New York: Teachers College Press.

[10]. Frederikson, P., Findlay, A., Furham, (2006). A relationship between gender and emotions between different cultures. Psychological Perspective. Cambridge University Press.

[11]. Fulk, B. M., Davido , L., \& Ferrari, S. (2003). Concerns about ninth-grade students' poor performance: One school's action plan. American Secondary Education, 31(2). 
[12]. Goleman, D. (1995). Emotional Intelligence: Why it matters more than IQ for character health and life long achievement. N.Y. Bantam Press.

[13]. Goleman, D. (1995). Emotional Intelligence, N.T. Bantam Press

[14]. Goleman, D. (1995). Emotional Intelligence: Issues on Paredigm building. In Cherniss and D. Goldman (Ed's), The imotionally intelligengence workplace, San Francisco: Jossey Bass.

[15]. Goleman, D. (1998). Working with Emotional Intelligence, N.T. Bantam.

[16]. Goleman, D. (1998). What makes a leader? Harvested Business Review,77,93-102.

[17]. Government of India. (1986). National Policy on Education. New Delhi: Ministry of Human Resource Development.

[18]. Government of India. (2000). Constitution of India. New Delhi.

[19]. Green, M., Lucy, Robin, White. (2011). Decision Trees, Howard School Press.

[20]. Jacobson,L.D.(2000). Editor's choice. Valuing diversity-student-teacher relationships that enhance achievement. Community College Review, 28(1)

[21]. O'Connor, C. \& Paunonen, V. (2006). Big five personality predictors of post secondary academic performance. Personality and Individual Differences 43 (5), 971-990.

[22]. Sebastian, C.R. (2008). A study of relationship between academic achievement, motivation and anxiety among undergraduate students of Jharkhand. Dissertation submitted for M.Phil, S.V.U. Tirupathi.

[23]. Sharma, K. R. (1991). Educational life style of tribal students: A study of secondary schools in Madhya Pradesh. New Delhi: Classical Publishing Company.

[24]. Sharma, R. C. (1984). Effect of incentive schemes on scheduled castes and scheduled tribes and girls. Rajasthan: SIERT.

[25]. Sharma, V.P. (1977). Some Personality Traits of the Scheduled Caste and Scheduled Tribe Pupils, Abstract of the papers published in part III of the Proceedings of the $64^{\text {th }}$ session of Indian Science Congress.

[26]. Sharma, V. P. (1980). Personality dynamics of tribals of Bastar (pilot observation). Report of ICP, Symposium on parent child interaction, Sagar.

[27]. Sijhora, J.S. (1977). A comparative study of personality Traits of Oraon and Bhil students. Abstract of the paper published in Part III of the proceedings of the $64^{\text {th }}$ session of IndianScience Congress Association.

[28]. Sujata, K. (1998). Education among the scheduled Tribes in India. NCERT New Delhi.

[29]. Toppo, S. (1974). Education then and now Among the Oraon. Ph.D. Education, Ranchi University. 